\title{
Solitary Neurofibroma of Palatine Tonsil- A Case Report
}

\author{
Vageesh PB${ }^{1}$, Manjari K²*, Priya $\mathbf{M}^{1}$ and Kanwar $\mathbf{S}^{1}$ \\ ${ }^{1}$ Department of Otorhinolaryngology and Head and Neck surgery, Dr Ram Manohar \\ Lohia Hospital, India \\ ${ }^{2}$ Department of Pathology, Dr Ram Manohar Lohia Hospital, India
}

*Corresponding author: Manjari Kishore, Senior Resident, Department of Pathology,

Dr Ram Manohar Lohia Hospital, New Delhi-110001, India, Tel: +918105104471; E-mail: drmanjarik@gmail.com

\section{Case Report \\ Volume 3 Issue 1}

Received Date: May 04, 2018

Published Date: May 17, 2018

DOI: $10.23880 /$ ooaj-16000167
Keywords: Solitary Neurofibroma; Palatine tonsils; Schwannomas

Abbreviations: BPNSTs: Benign Peripheral Nerve Sheath Tumors; CECT: Contrast Enhanced Computed Tomography

\section{Introduction}

Neurofibromas have been commonly described in the head and neck region with its presentation in the soft tissues of the lateral cervical region and in the pharynx [1]. However its description in oral cavity, pharynx and palatine tonsils are extremely rare. Neurofibromas, Schwannomas and perineuromas have been described under benign peripheral nerve sheath tumors (BPNSTs) and are regarded as distinct entities [2]. Here we report a rare case of solitary neurofibroma of palatine tonsil in an 18 year old Indian female patient, whom we believe to be the third such case reported in world literature till date.

\section{Case Report}

\section{Clinical and Radiological Features}

An 18 year old Indian female patient presented to our department with history of slowly progressive painless swelling in the left side of the throat past 1 year. She also complained of change in voice, snoring and progressive increase in discomfort while swallowing which radiated to the left ear. There was no history of pigmented cutaneous/ mucosal lesion nor any history of neural tumors which were suggestive of neurofibromatosis. Clinical examination revealed a single globular mass in the oropharynx measuring approximately $4^{*} 4 \mathrm{~cm}$ pushing the uvula superiorly, tonsils laterally and touching the posterior pharyngeal wall posteriorly (Figure 1). On palpation the mass was firm, non tender and was probably attached to the posterior pillar of the left tonsil. No palpable cervical lymph nodes nor any stigmata of neurofibromatosis was seen. Diagnositic nasal endoscopy was found to be normal. A contrast enhanced Computed Tomography (CECT) revealed a well defined pedunculated non enhancing cystic lesion of size $3 * 2.5 \mathrm{~cm}$ arising from the left lateral pharyngeal wall at C2-C3 level with partial airway obliteration, most likely a pharyngeal retention cyst (Figure 2). Patient underwent an elective tracheostomy to secure the airway. Patient was placed in Rose's position and oropharyngeal mass was found to have its only attachment to the posterior pillar of left tonsil (Figure 3). Complete excision was performed and patient was decannulated subsequently the next day. The patient recovered unremarkably and subsequent follow up did not show any evidence of recurrence.

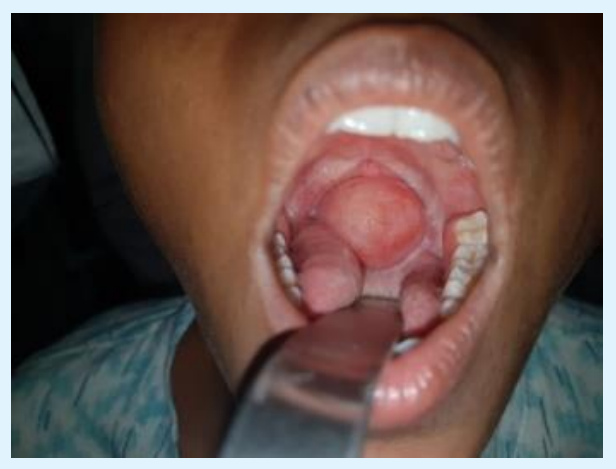

Figure 1: Globular mass in the oropharynx arising from the posterior pillar of left tonsil. 


\section{Otolaryngology Open Access Journal}

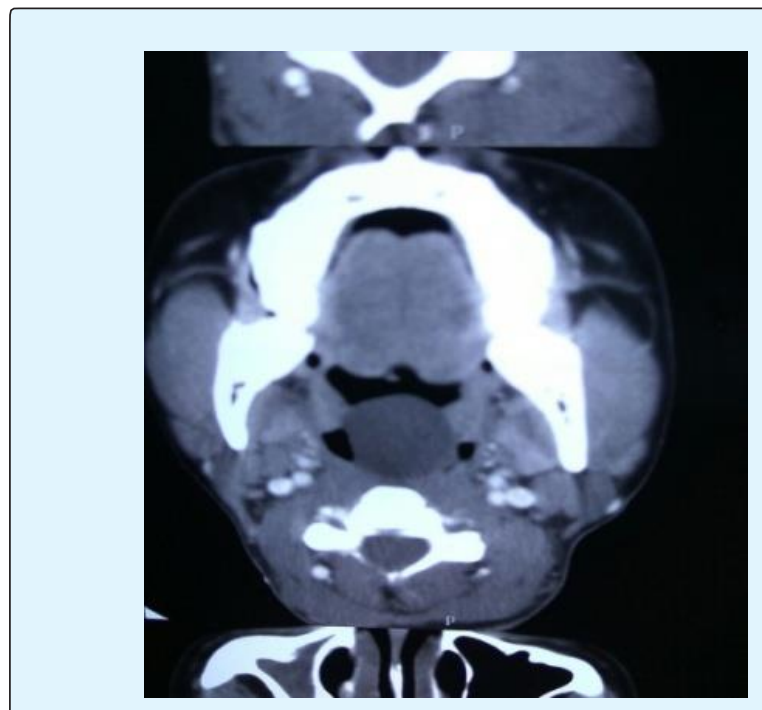

Figure 2: Non- enhancement of lesion on Contrast enhanced computed tomography (CECT).

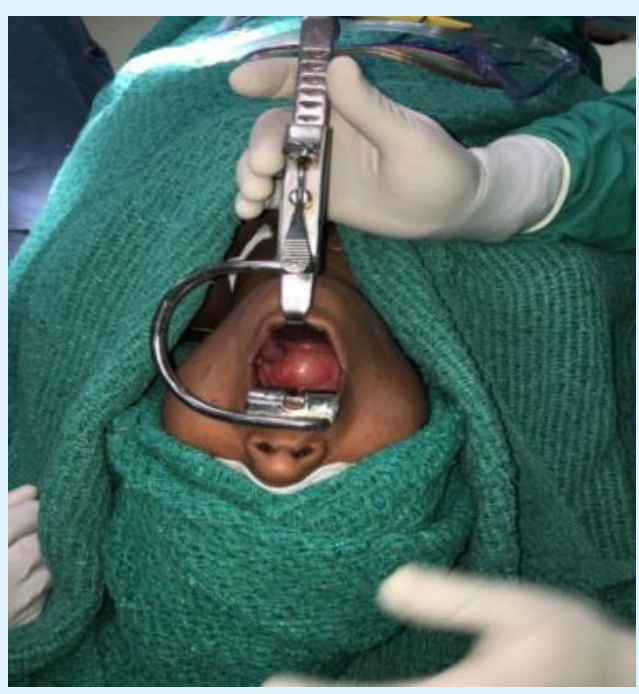

Figure 3: Patient placed in Rose position prior to excision of lesion.

\section{Pathological Findings}

Macroscopically the specimen measured around $4 * 2.5^{*}$ $2.5 \mathrm{~cm}$ and consisted of pale grey mass (Fig 4A). Microscopically, it consisted of cells arranged in fascicles and interlacing bundles of spindle cells containing thin wavy nucleus and scanty cytoplasm intermixed with dense bundle of collagenous fibres (Fig 4B\&C). There was no evidence of Antoni A nor Antomy B type patterns nor presence of an associated peripheral nerve. Mitotic figures were absent. Immunohistochemical staining showed the spindle cells to be diffusely positive for S-100 protein (Fig 4D). These features were consistent with neurofibroma of the palatine tonsil.

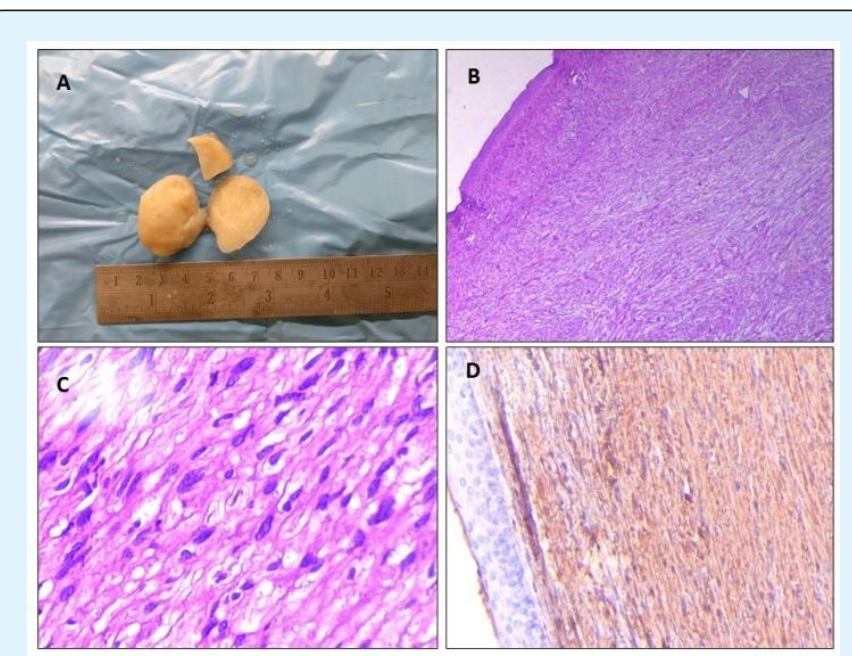

Figure 4: Spindle cells showed positive staining with S100 on immunohistochemistry.

\section{Discussion}

Neurofibromas of the head and neck usually manifest as deep seated tumors while its presentation in the oropharyx is extremely rare. The risk of malignant transformation has been reported between 5-12\%, especially when associated with Von Recklinghausens disease [3]. Amongst BPNSTS; schwannomas, neurofibromas and perineuroma are regarded as distinct entities [2]. Neurofibromas have been suggested to have a mixed or hamartomatous origin owing to the presence of distinct cell types which are derived from both neural crest and mesenchymal precursors [4]. Neurofibromas in contrast to schwannomas, are less cellular, looser in texture and don't exhibit the characteristic pattern of alternating Antony A and Antony B. However various electron microscopic, immunohistochemical and tissue culture studies support an alternative hypothesis that neurofibromas may result from divergent differentiation of a single cell type [5]. This is supported by the documentation of somatic loss of heterozygosity and mutation of the neuro bromatosis 1 (NF1) gene in NF1associated neurofibromas [6]. By definition, solitary neurofibromas constitute $90 \%$ of all neurofibromas and affect patients who do not have neurofibromatosis [7]. They affect men and woman equally and mostly appear during the third and fourth decades of life. 


\section{Otolaryngology Open Access Journal}

Neurofibromas have been described in various forms: cutaneous neurofibromas (both localized and diffuse types), intraneural neurofibromas (localized and plexiform), massive soft-tissue neurofibromas (diffuse and plexiform), and visceral neurofibromas (solitary or multiple, sporadic or associated with neurofibromatosis [von Recklinghausen's disease]). The clinical presentation and gross appearance of these forms differ considerably despite of their common cellular makeup. The diagnostic workup should include a search for more than one neurofibroma and identification of one or more clinical features such as café au lait macules, cutaneous and mucosal nodules. Family history of similar lesions should be solicited. Other investigations should include puretone audiometry to exclude bilateral neural hearing loss, an ophthalmologic examination to look for Lisch nodules (iris hamartoma), CT or MRI of the head and neck to search for other tumors (e.g., glioma, meningioma, and astrocytoma), and abdominal scanning for pheochromocytoma. Genetic tests for gene mutations might be performed if feasible. An extensive study of literature yielded only 2 cases of solitary neurofibroma limited to the oropharyx. The first case was reported in 2002 by Surwald, et al. reported the first case of solitary neurofibroma of the palatine tonsil, which occurred in a 28-year-old white man in the United Kingdom [8]. The second case was reported in 2007 by Madhumita, et al. in a 49 year old Indian woman [9].

\section{Conclusion}

Neurofibromas are usually solitary tumors, however upto a tenth of patients have multiple lesions [8]. In the head and neck, neurofibromas usually present as a painless mass invariably compressing surrounding vital structures and hence interfering with phonation, deglutition or respiration requiring early surgical intervention.

\section{References}

1. Hamza A, Fagan JJ, Weissman JL, Myers EN (1997) Neurilemmomas of the parapharyngeal space. Arch Otolaryngol Head Neck Surg 123: 622-626.
2. Woodruff JM (1991) Tumors and tumor like conditions of the peripheral nerve. In: Chung EB, et al. (Eds.), Tumors and Tumorlike Lesions of Soft Tissue: Contemporary Issues in Surgical Pathology. New York, London: Churchill Livingstone 18: 205-228.

3. Rapado F, Simo R, Small M (2001) Neurofibromatosis type 1 of the head and neck: Dilemmas in management. J Laryngol Otol 115 (2): 151-154.

4. Erlandson RA, Woodruff JM (1982) Peripheral nerve sheath tumors: an electron microscopic study of 43 cases. Cancer 49(2): 273-287.

5. Kharbanda K, Dinda AK, Sarkar C, Karak AK, Mathur M, et al. (1994) Cell culture studies on human nerve sheath tumors. Pathology 26(1): 29-32.

6. Serra E, Rosenbaum T, Winner U, Aledo R, Ars E, et al. (2000) Schwann cells harbor the somatic NF1 mutation in neuro.bromas: evidence of two different Schwann cell subpopulations. Hum Mol Genet 9(20): 3055-3064.

7. Keel SB, Rosenberg AE (2001) Soft tissue pathology of the head and neck. In: Pilch BZ, Head and Neck Surgical Pathology. Philadelphia: Lippincott Williams and Wilkins, 2001: 417-418.

8. Surwald CJ, Salam MA, Rowe RC (2002) A solitary neurofibroma of the palatine tonsil. J Laryngol Otol 116 (12): 1050-1052.

9. Madhumita K, Nambiar A, Prathapan, P (2007) Solitary neurofibroma of the palatine tonsil: A case report. Ear Nose Throat J 86(12): 756-758.

10. Loree TR, North JH, Werness BA, Nangia R, Mullins AP, et al. (2000) Malignant periperhal nerve sheath tumors of the head and neck: analysis of prognostic factors. Otolaryngol Head Neck Surg 122: 667-672. 